\title{
Dual-Pump CARS Measurements in the University of Virginia's Dual-Mode Scramjet: Configuration " $A$ "
}

\author{
Andrew Cutler ${ }^{*}$, Gaetano Magnotti ${ }^{\dagger}$, Luca Cantu $^{\dagger}$, Emanuela Gallo ${ }^{\dagger}$ \\ The George Washington University, Mechanical and Aerospace Engineering, \\ 1 Old Oyster Point Road, Suite 200, Newport News, VA, 23602 \\ Paul. M. Danehy \\ NASA Langley Research Center, Hampton, VA, 23681 \\ Robert Rockwell ${ }^{\S}$, Christopher Goyne ${ }^{* *}$, and Jim McDaniel ${ }^{\dagger \dagger}$ \\ University of Virginia, Mechanical and Aerospace Engineering, Charlottesville, VA 22904
}

\begin{abstract}
In this paper we describe efforts to obtain canonical data sets to assist computational modelers in their development of models for the prediction of mixing and combustion in scramjet combustors operating in the ramjet-scramjet transition regime. The CARS technique is employed to acquire temporally and spatially resolved measurements of temperature and species mole-fraction at four planes, one upstream of an $\mathrm{H}_{2}$ fuel injector and three downstream. The technique is described and results are presented for cases with and without chemical reaction. The vibrational energy mode in the heated airstream of the combustor was observed to be frozen at near facility heater conditions and significant nonuniformities in temperature were observed, attributed to non-uniformities of temperature exiting the heater. The measurements downstream of fuel injection show development of mixing and combustion, and are already proving useful to the modelers.
\end{abstract}

\section{Introduction}

Under the auspices of the National Center for Hypersonic Combined Cycle Flow Propulsion, ${ }^{1}$ a series of dualmode scramjet experiments are being conducted with the aim of examining the flow processes that take place in the isolator and combustor of a direct-connect scramjet model that is operated at flight enthalpy of Mach 5, and to obtain benchmark data sets in order to validate numerical models. These experiments were performed at the University of Virginia's Supersonic Combustion Facility. The scramjet combustor has optical access suitable for the application of advanced optical measurements techniques, while the long duration testing capability of the facility allows large data sets to be built up at a fixed test point and pointwise statistics of the flow variables to converge. For comparison, a current state of the art data set, the SCHOLAR experiment ${ }^{2}$, which contains measurements of temperature and composition in several planes in a hydrogen-fueled supersonic combustor measured with the dualpump Coherent Anti-Stokes Raman Scattering (CARS) technique, was limited by short runs, resulting in poorly converged turbulent fluctuation statistics and limited spatial resolution. Other highly detailed data sets, such as the Test Media Effects coaxial supersonic combusting jet experiment, ${ }^{3,4}$ are for more simple canonical flows rather than the dual-mode scramjet flow described herein. The diagnostics are aimed at capturing the physics of turbulent reacting flows, and many of the measurement techniques are spatially and temporally resolved. In particular, turbulent fluctuation flow statistics are being examined using dual-pump CARS. Additional diagnostics of Planar Laser Induced Fluorescence (PLIF), Particle Imaging Velocimetry (PIV), and Line of Sight (LOS) and tomographic Tunable Diode Laser Spectroscopy (TDLAS) will result in databases that are unique in their level of detail and highly suited to model development and validation. Use of multiple and partially redundant instrumentation will give a good understanding of the data uncertainties. In this work we report the CARS measurements in the first configuration of the scramjet ("Configuration A" 5 ).

Coherent anti-Stokes Raman spectroscopy (CARS) is a non-linear spectroscopic technique in which three laser beams, two pump beams and a Stokes beam, are focused and crossed at their focal point, and a fourth signal laser

\footnotetext{
${ }^{*}$ Professor. Associate Fellow AIAA

${ }^{\dagger}$ Graduate student. Member AIAA

${ }^{*}$ Research Scientist. Associate Fellow AIAA

$\S$ Senior Scientist. Member AIAA

${ }^{* *}$ Research Associate Professor, Associate Fellow AIAA

${ }^{\dagger}$ Professor, Associate Fellow AIAA
} 
beam is generated at the intersection through a four-wave mixing process. Resonances associated with Raman active molecular rotational-vibrational transitions strengthen the CARS signal in a manner dependent on gas composition and temperature. The wavelength of excitation or "Raman shift" corresponds to the difference in energy between a pump beam and a Stokes beam (longer wavelength) photon. In the broadband CARS technique, one of the laser beams, the Stokes beam, is spectrally broad whereas the other pump beams are spectrally narrow; this enables multiple resonances to be excited simultaneously. The signal beam is spectrally broad and carries with it the spectral signature of the gases present (over some range of wavelengths). This signal beam is dispersed by a spectrometer and spectra are compared to analytical spectral models to obtain information on composition and temperature. In the dual-pump CARS technique, originally developed by Lucht and coworkers, ${ }^{6,7}$ the two pump beams are at different wavelengths and two different ranges of Raman shift may be accessed. The CARS method employed in this work is based on the techniques developed at NASA Langley, ${ }^{3,8,9,10,11}$ particularly those described in a companion paper by Magnotti. ${ }^{12}$

\section{Test Facility and Dual-Mode Scramjet}

\section{A Experiment}

The experiment was conducted using the University of Virginia's Supersonic Combustion Facility (UVaSCF). This facility is an electrically heated, continuous flow scramjet wind tunnel that is operated in direct-connect mode. It is capable of simulating Mach 5 flight enthalpy and provides a clean test flow that is free of contaminants (such as those from a vitiation heater). Facility run times of the order of five hours or more are possible and, because of good optical access and proximity to laser diagnostics labs, the facility is well suited to the application of advanced instream diagnostics such as CARS. The facility flow conditions are presented in Table 1and these conditions were typically maintained to within $\pm 1 \%$ during a run and across multiple runs. The facility is fully described elsewhere. ${ }^{13,14}$

Table 1. Test conditions for air flow and hydrogen fuel.

\begin{tabular}{lllll}
\hline \hline Parameter & Air & Fuel & Error $^{\mathrm{b}}$ \\
\cline { 2 - 4 } & Total pressure $(\mathrm{kPa})$ & 300 & 465 & $\pm 3 \%$ \\
& Total temperature $(\mathrm{K})$ & 1200 & 300 & $\pm 3 \%$ \\
& Mach number $^{\mathrm{a}}$ & 2.0 & 1.7 & \\
& Static pressure $^{\mathrm{a}}(\mathrm{kPa})$ & 38 & 94 & \\
& Static temperature $^{\mathrm{a}}(\mathrm{K})$ & 667 & 190 & \\
Equivalence ratio & & 0.17 & $\pm 5 \%$ \\
${ }^{\text {a }}$ Property at nozzle exit determined using nozzle area ratio and assuming isentropic flow $(\gamma=1.4)$.
\end{tabular}

Figure 1 presents a schematic of the dual-mode scramjet flow path that was used for the CARS measurements. ${ }^{5}$ The flow path consists of a Mach 2 facility nozzle that is directly coupled to a rectangular combustor. The combustor is $25.4 \mathrm{~mm} \times 38.1 \mathrm{~mm}(1$ " $\times 1.5$ ") in cross section at the entrance. One of the walls houses an unswept ramp fuel injector through which hydrogen fuel is injected. The ramp is $12.7 \mathrm{~mm}(0.5$ ") wide and the forward face is angled $10^{\circ}$ to the injector wall. The injector-wall-normal height (h) is $6.35 \mathrm{~mm}(0.25$ "); this height is used to nondimensionalize the spatial variables. Fuel injection takes place though a conical Mach 1.7 nozzle at the base of the ramp with axis parallel to the ramp face. All walls in the flow path are parallel except for the wall that houses the fuel injector. This wall has a $2.9^{\circ}$ divergence that begins at the leading edge of the ramp fuel injector. The divergence results in the ramp face having an angle of incidence to the incoming flow of $7.1^{\circ}$. The combustor divergence continues through the duct and terminates with an atmospheric backpressure at the exit of the extender section at $366 \mathrm{~mm}$ downstream of the ramp. The combustor total length is $470 \mathrm{~mm}$ (18.5"). All components in the flow path were made of stainless steel and the walls in the combustor section, including the ramp, were coated in a $0.38 \mathrm{~mm}$ thick layer of thermal barrier zirconia. The wall that houses the fuel injector is instrumented with 46 low frequency pressure taps that are mostly aligned on the combustor centerline. Type K thermocouples are also located in the wall along the centerline at six axial stations downstream of fuel injection. Reference 5 provides further details on the flow path and instrumentation. 
The four CARS measurement planes that were used in this study are presented in Figure 1. Normalized by the normal height of the ramp, the planes were at $\mathrm{x} / \mathrm{h}=-10.4,6,12$, and 18 relative to the point of fuel injection. Measurements at the upstream plane were intended to quantify the upstream boundary condition in the combustor, while the purpose of the three downstream planes was to enable interrogation of the fuel-air mixing and combustion zone downstream of fuel injection. To enable measurements at each plane, the two side walls of the flowpath each incorporated a $3.18 \mathrm{~mm}$ wide slot that spanned the entire height of the duct. This enabled CARS measurements over the entire cross plane at each axial station. When measurements were not conducted at a particular plane the slots were filled with a stainless steel plug. The active slots were sealed from the atmosphere using an offset window arrangement that located the windows away from the flow path by $127 \mathrm{~mm}$. This distance was required to prevent damage to them by the focused laser beams. The internal volume formed by the offset windows and the slots was purged by a total of 3 to 4 SCFM of unheated air during the facility operation that flowed through the slots into the scramjet. This prevented a buildup of fuel and combustion products in the volume. The purge air volumetric rate is roughly $1 / 500^{\text {th }}$ of the volumetric flow rate in the scramjet and was found (by varying the flow rate) to produce a small (in the non-reacting case) or no (in the reacting case) affect on the pressure distribution in the duct downstream of the slots, and none upstream of the slots.

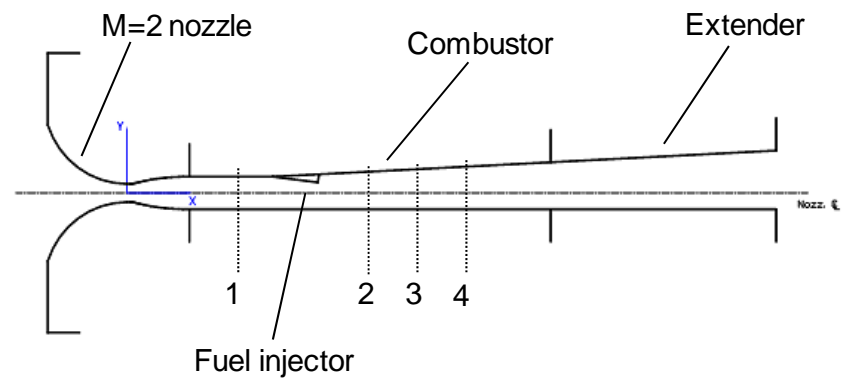

Figure 1. Dual-mode scramjet flow path used for CARS measurements. CARS measurement planes marked 1 to 4 . The $x$-coordinate is referenced to the base of the injector.

As presented in Table 1, the scramjet flow path was normally fueled at an equivalence ratio $(\varphi)$ of 0.17 (although in one case, due to problems with the fuel system, it was operated at $\varphi=0.12$ ). Since the flow static temperature in the combustor was below the autoignition temperature of the fuel, measurements could first be performed for the case of fuel-air non-reacting. A back-pressuring procedure was then used for initial ignition of the combustor. This procedure consisted of lowering the facility stagnation pressure at the same time as introducing fuel. The increased backpressure to facility pressure ratio resulted in a shock train that extended upstream towards fuel injection and ignited the fuel-air mixture. Combustion was self sustaining following ignition and as the facility pressure was raised to the nominal test condition. Measurements were then repeated for the fuel-air reacting case. This approach enabled the effect of the heat release of combustion on the fuel-air mixing process to be examined. After completing CARS measurements at a plane for the cases of fuel-air non-reacting and fuel-air reacting, the facility was shut down and the window offset assembly was moved. The tests were then repeated for other planes in separate wind tunnel runs.

Data acquisition for the scramjet flow path parameters was performed using a NetScanner ${ }^{\mathrm{TM}}$ pressure scanner that was operated with a remote NetScanner ${ }^{\mathrm{TM}}$ thermocouple unit. Typically a scan of 20 samples was acquired over $2 \mathrm{sec}$. at a sample rate of $10 \mathrm{~Hz}$ for each pressure tap and thermocouple. Quantities for each tap or thermocouple were then averaged prior to plotting. Pressure and temperature were typically measured to within $\pm 0.5 \%$ and average quantities typically had a $95 \%$ confidence interval of no more than $\pm 1.5 \%$.

\section{B Wall Pressure Results}

Typical averaged pressures measured along the scramjet flowpath are presented in Figure 2. Pressure distributions are shown for the cases of fuel off, fuel-air non-reacting and fuel-air reacting with $\varphi=0.17$, and fuel-air non-reacting with $\varphi=0.123$. Axial distances have been normalized by the normal height of the ramp and are referenced to the point of fuel injection while pressures are normalized by the pressure measured at the most upstream axial station $(37 \mathrm{kPa})$. Referring first to the fuel off distribution, the presence of the ramp results in a shock wave that is evident at $\mathrm{x} / \mathrm{h}=-6$, this is followed by an expansion at the base of the ramp. Reflection of these waves follows downstream followed by a rise in pressure at $\mathrm{x} / \mathrm{h}=20$ that is the result of the 1 atmosphere backpressure on the flowpath at $\mathrm{x} / \mathrm{h}=58$. When fuel is introduced into the flowpath but not ignited, it can be seen in Figure 2 that the pressure distribution is only slightly changed from the fuel-off case (for both $\varphi=0.17$ and 0.123 ). The minor changes 
are the result of the presence of the fuel jet and the changes in flow properties that result as the fuel and air mix. It is evident for this case that CARS slot 1 is operating in a mildly adverse pressure gradient while slots 2 to 4 are generally in a favorable pressure gradient. When the fuel-air mixture is ignited, it can be seen that combustion leads to a significant pressure increase in the scramjet flow path. Importantly, the pressure rise does not extend upstream of the ramp fuel injector for this equivalence ratio. This mode of operation is referred to as the scram mode. This means that the inflow (just upstream of the ramp) is supersonic although the flow downstream is a mixture of supersonic and subsonic flow. Since the inflow is supersonic there is still a shock generated pressure rise that is caused by the ramp and this is evident at $\mathrm{x} / \mathrm{h}=-6$. However, unlike the non-reacting and fuel-off cases, the pressure monotonically increases downstream of the fuel injector all the way to the exit of the combustor at $\mathrm{x} / \mathrm{h}=58$. For this fuel-air reacting case, CARS slot 1 is still in a mildly adverse pressure gradient while slots 2-4 are now also in an adverse pressure gradient.

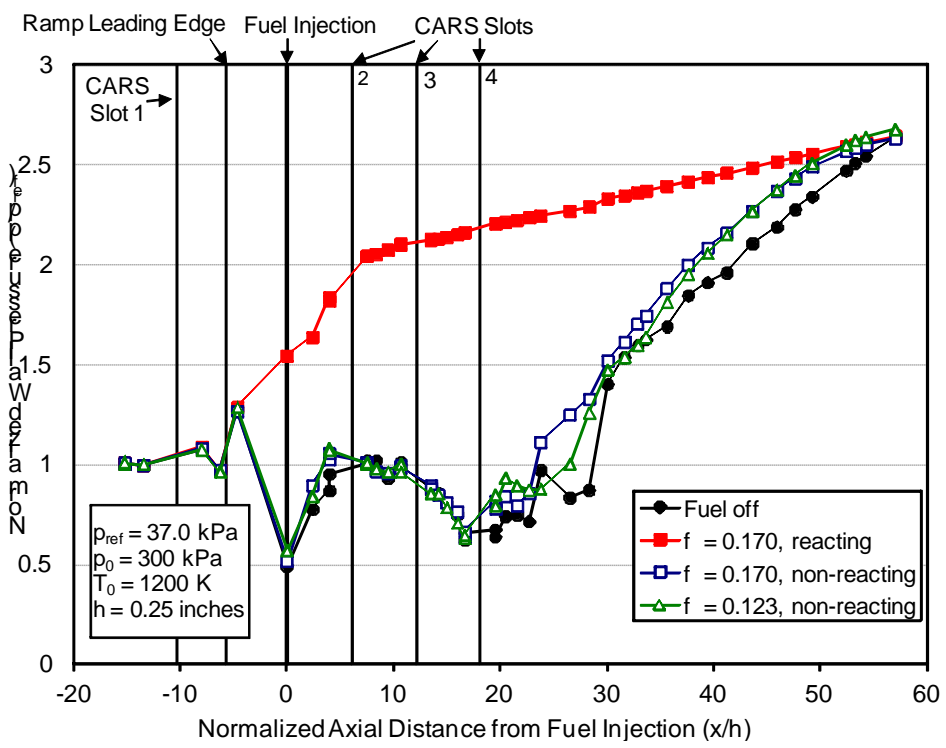

Figure 2. Axial pressure distribution in scramjet flow path for fuel off, fuel-air non-reacting and fuel-air reacting. CARS measurement planes are marked 1 to 4.

\section{CARS Methods}

\section{A Optical System}

The optical system, illustrated in Figure 3, consists of a mobile laser cart (not shown), located in a room adjacent to the scramjet lab, and components located in the scramjet lab. Mirrors relay the laser beams to a stepping-motor driven beam translation system, upon which transmission optics (on one board) and collection optics (on a second board) are mounted. These components are mounted on a large optical table adjacent to the facility.

The laser cart contains an injection seeded Nd:YAG laser, frequency doubled to $532 \mathrm{~nm}$, a narrow band dye laser (Spectra Physics PDL-2) centered at around either $550 \mathrm{~nm}$ (reacting cases) or $553 \mathrm{~nm}$ (non-reacting cases), and a home-built broadband dye laser centered at $603 \mathrm{~nm}$, with FWHM of $10 \mathrm{~nm}$. The pulse width of the laser is $8 \mathrm{~ns}$ and the repetition rate is $20 \mathrm{~Hz}$. We chose a planar BOXCARS geometry with the narrowband dye laser and broadband dye laser collinearly overlapped at the laser cart. The cart also contains spherical-lens telescopes for controlling beam size and divergence, and a rotatable half-wave plate and polarizing beam cube combination that allows the energy of the Nd:YAG laser beam to be controlled. Laser energies at the measurement volume were typically 62 $\mathrm{mJ}, 32 \mathrm{~mJ}$ and $19 \mathrm{~mJ}$ for the Nd:YAG, the narrowband and the broadband dye laser respectively.

Located on the transmission board, shown in Figure 4, are mirrors that cross the Nd:YAG and overlapped dye laser beams (crossing angle of $3.9^{\circ}$ ), a $750 \mathrm{~mm}$ lens for focusing the dye laser beams, and a $600 \mathrm{~mm}$ lens for focusing the Nd:YAG. The latter lens is tilted with respect to the incoming beam so that, by introducing astigmatism, it shapes the focal spot at the beam crossing to a roughly 4:1 axis ratio ellipse with major axis orthogonal to the plane formed by the three laser beams. This helps in reducing beam steering effects in flows with large, unsteady density gradients. ${ }^{15}$ The focal length of the two lenses is long enough to ensure that laser irradiances are below the Stark broadening and stimulated Raman pumping thresholds determined in Ref. 11. To view the beams at their crossing point a splitter (uncoated wedged glass plate) is located after the focusing lenses which direct 
a small fraction of the beams energy towards a secondary beam intersection. ${ }^{16} \mathrm{~A}$ microscope objective lens, filters, and a CCD camera are used to detect the image of the beam crossing. This beam viewing system is used to set the focus, lens twist, and location of the beams at the crossing plane. The wedged glass plate is removed during data acquisition.

Located on the collection optics board is a $600 \mathrm{~mm}$ collimating lens, a series of dichroic mirrors that reflect and separate the signal while transmitting the Nd:YAG beam upon which it is superimposed. A second beam viewing system is placed after the measurement volume which uses a splitter, and an achromatic lens to focus and cross the beams in front of a camera. The second system is used to monitor and realign the beams during a test.

The signal is relayed back to the optical table through filters that remove remaining Nd:YAG light, a polarizer, and a spherical lens that focuses the signal at the entrance plane of a $1 \mathrm{~m}$ spectrometer with 2400 lines per mm grating. The horizontally dispersed signal is recorded at the exit plane by an unintensified, scientific-grade, backilluminated CCD camera. The pixels of the camera are binned into 3 bins vertically $\times 1340$ pixels horizontally; the CARS signal is focused on the center bin. For additional details, see Magnotti et al. ${ }^{12}$

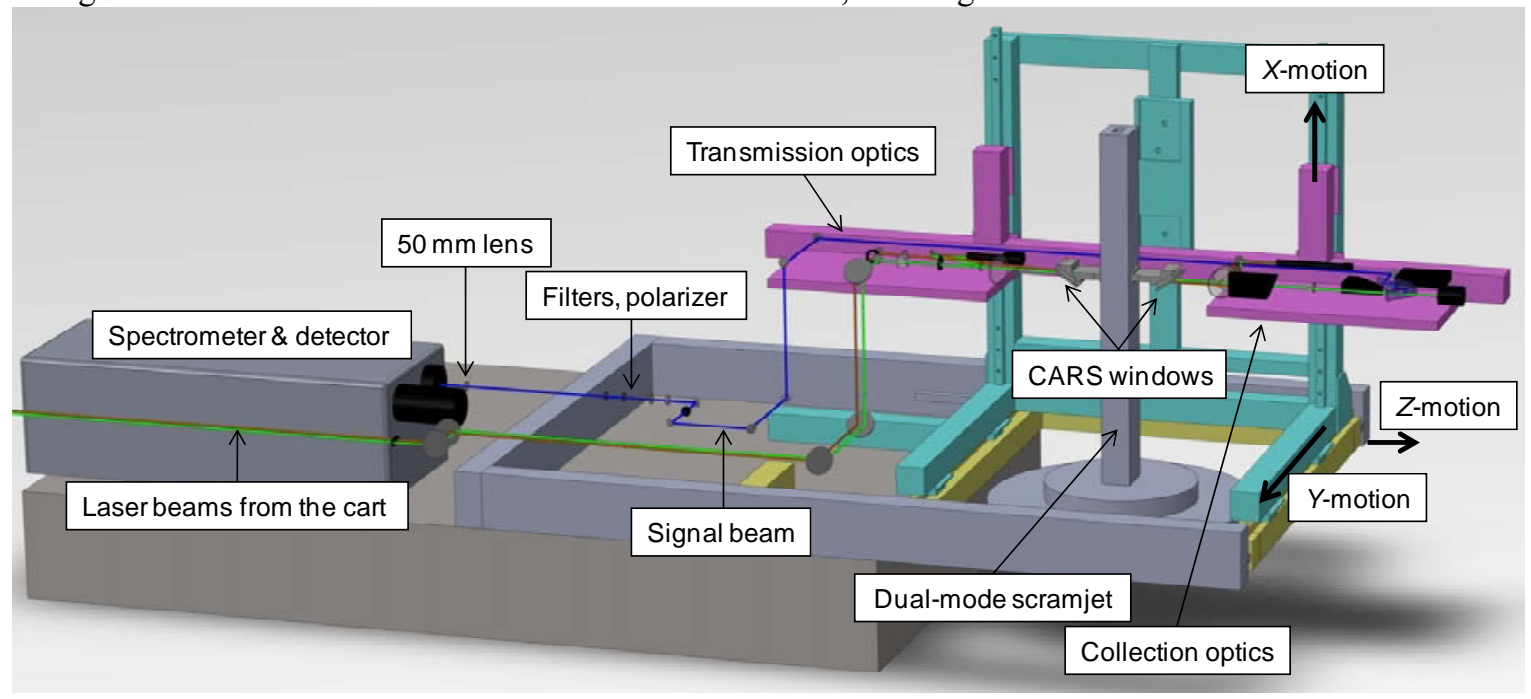

Figure 3. Optical system located in the scramjet lab.

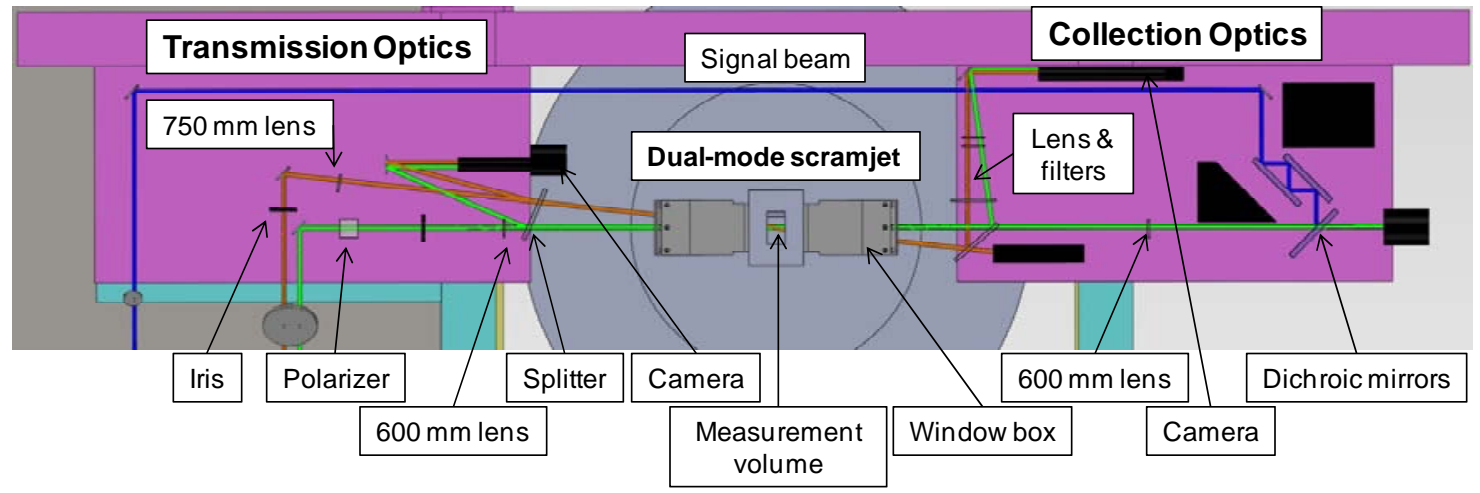

Figure 4. Transmission and collection optics.

\section{B Method}

For safety reasons (the beams can be viewed without safety glasses), the optical system is aligned initially using green and red low-power (Class 3R) CW laser beams, which are injected into the system with flip-up mirrors, and irises are aligned to the beams. Beam crossing is ensured with the beam viewing system. Residual green light reflected by the dichroic mirrors follows the signal path and is used to align the signal path to the spectrometer. Once aligned, the CW laser beams are removed by lowering the flip mirrors and the CARS laser beams are aligned to the irises. Additional focusing and adjustments of the CARS lasers beams at the crossing are accomplished using the beam viewing system. During operation of the facility, access to the scramjet lab is limited to 15 minutes per day due to the high acoustic levels in the lab, and prohibited when fuel is flowing. Alignments of the beam crossing 
are accomplished at the laser cart and by remotely turning the final mirror on the dye laser beams path, which is mounted in a picomotor controlled mount.

Once the scramjet facility flow and heater are brought to the test condition, the measurement volume is translated out of the scramjet model to an adjacent small low speed argon jet and reference CARS spectra (typically 500 laser shots) are acquired. A second set of reference spectra are acquired after completion of the test. The fuel flow in the model is then initiated and the measurement volume translated to map out the flow on a rectangular grid of from 169 to 230 points, including a number of points out of the tunnel flow in the slot of model wall. (These measurements in the cooler window purge flow were useful in verifying the location of the measurement volume.) Except for a few locations, 200 individual CARS spectra are acquired at each location. The order of the locations is randomized to identify and randomize the effects of systematic error trends. In the reacting case, signal varies by two orders of magnitude from low levels in the hot products of combustion, to much higher levels in the free stream. To maintain adequate signal at high temperatures, while not saturating the detector at low temperatures, the energy of the $532 \mathrm{~nm}$ CARS beam was adjusted (under automatic computer control) using the wave plate and polarizer combination on the laser cart.

\section{Analysis of CARS Spectra}

The CARS measured spectra were first preprocessed to obtain the CARS susceptibility spectra. The processed spectra were then fitted to theoretical spectra to obtain temperature and composition as parameters of the fit.

The preprocessing consists of first subtracting the background from the spectra, consisting of the instrument baseline signal level plus the signal associated with any contaminating light source, such as non-CARS emission from the flow field or room light. The background was taken to be the signal measured in bins 1 and 3 of the CCD, above and below the bin where the signal was located (bin 2). The spectrum was then normalized by the argon reference spectrum, which is the argon spectrum with background subtracted and averaged over typically 200 shots. The reference spectrum was interpolated, linearly in time, from the argon spectrum acquired before the test was started and the spectrum acquired after the test was complete.

The fitting method employs a library of theoretical spectra calculated separately using the Sandia CARSFT code ${ }^{17}$ modified by Lucht ${ }^{7}$ for dual-pump CARS and further modified by O'Byrne ${ }^{9}$ and us. Theoretical spectra are interpolated from the library at each iteration of the fitting algorithm. ${ }^{10}$ The algorithm finds the parameters of the fit, which are the temperature, mole fractions of resonant species, and a constant wavelength shift (to account for small movements of the CARS signal at the entrance of the spectrometer), by a weighted least-square fit to the experimental signal intensity. ${ }^{10}$ Libraries are "sparse" to enable rapid fitting with several resonant chemical species. ${ }^{10}$ In the reacting test cases the fitted resonant species were $\mathrm{N}_{2}, \mathrm{O}_{2}$, and $\mathrm{H}_{2}$ ( 3 species variables), while $\mathrm{H}_{2} \mathrm{O}$ was the remaining major species (which was non-resonant and can be estimated by difference). In the non-reacting cases we typically fitted for $\mathrm{H}_{2}$ and "air" ( 2 species variables), both resonant, while the non-resonant species was taken to have the same susceptibility as $\mathrm{H}_{2}$. The air was modeled as $21 \% \mathrm{O}_{2}$ and $79 \% \mathrm{~N}_{2}$ in fixed ratio.

As will be discussed in the results, we observed that there was significant vibrational non-equilibrium in the $\mathrm{N}_{2}$ and to a lesser extent in the $\mathrm{O}_{2}$, in the freestream but not in the fuel plume (consisting of $\mathrm{H}_{2}$, air, and combustion products). This was shown not to be an effect of high irradiance (stimulated Raman pumping, which is know to create non-equilibrium vibrational populations ${ }^{11}$ ) in experiments in which the laser energies were varied. We did not attempt to fit the vibrational temperature as part of our analysis of full data set since the library fitting algorithm was not suited to this. However, CARSFT was modified to be able to specify separate vibrational and rotational temperatures of both $\mathrm{N}_{2}$ and $\mathrm{O}_{2}$. Thus, for library entries where the temperature was greater than $500 \mathrm{~K}$ and less than or equal to $1000 \mathrm{~K}$, and $\mathrm{H}_{2}$ mole fraction was less than $5 \%$, the vibrational temperature of $\mathrm{N}_{2}$ was set to $1200 \mathrm{~K}$ and of $\mathrm{O}_{2}$ was set to $950 \mathrm{~K}$; otherwise it was set equal to the rotational temperature (equilibrium). Library (rotational) temperatures (the fitted parameter) were in $200 \mathrm{~K}$ increments from $200 \mathrm{~K}$ to $1000 \mathrm{~K}$ for the non-reacting cases and from $200 \mathrm{~K}$ to $2600 \mathrm{~K}$ for the reacting cases.

The $\mathrm{N}_{2}$ and $\mathrm{O}_{2}$ spectra were modeled by the CARSFT code using the Voigt line shape model while was $\mathrm{H}_{2}$ was modeled using the Galatry model with variable narrowing parameter. ${ }^{12,18}$ The second pump frequency offset was $712-714 \mathrm{~cm}^{-1}$ for the non-reacting cases and was $618-621 \mathrm{~cm}^{-1}$ for the reacting cases. (The larger offset for the nonreacting cases was to raise the intensity of the signal from the $\mathrm{H}_{2}$ lines by moving the frequency difference between the narrow-band and broad-band dye lasers towards the Raman shift of $\mathrm{H}_{2}$, at the expense of bringing the $\mathrm{O}_{2}$ spectrum closer to the $\mathrm{N}_{2}$ spectrum.) Both pump line widths were assumed to be negligible and the instrument line width was in the range $0.77-0.90 \mathrm{~cm}^{-1}$. The shape of the CARS spectra depends weakly on pressure - pressure at a measurement point was taken to be the pressure at the wall, interpolated from the pressure tap measurements to the same axial location, and varied from $0.22 \mathrm{~atm}$ to $0.81 \mathrm{~atm}$ (see Figure 2). 


\section{CARS Results}

Figures 5 and 6 show experimental spectra and theoretical fits. These spectra and fits were averaged over 200 shots. The horizontal axis is the signal frequency minus the frequency of the narrow-band dye laser, which corresponds to the Raman shift for $\mathrm{N}_{2}$ and $\mathrm{H}_{2} \mathrm{~S}(9)$ spectra, and to the Raman shift minus the pump 2 offset for $\mathrm{O}_{2}$ and $\mathrm{H}_{2} \mathrm{~S}(4$ and 6$)$. The vertical axis is the square root of intensity, proportional to the CARS susceptibility. Also shown are histograms of fitted temperature.

Figure 5(a) shows typical results at $\mathrm{x} / \mathrm{h}=18$, non-reacting $(\varphi=0.12)$, in the freestream of the flow. The theoretical fit assumes the vibrational temperature of $\mathrm{N}_{2}$ is $1200 \mathrm{~K}$ (the nominal facility stagnation temperature) and that the vibrational temperature of $\mathrm{O}_{2}$ is $950 \mathrm{~K}$. Also shown is a theoretical spectrum at the same (rotational) temperature and composition as the fit but for which the vibrational temperatures are set equal to the rotational. The difference is not large for $\mathrm{O}_{2}$ but is very significant for $\mathrm{N}_{2}$ where the vibrational non-equilibrium results in a very pronounced "hot band" ( $1^{\text {st }}$ vibrationally excited level) absent in the equilibrium spectrum. Good agreement in this case suggests that the assumed vibrational temperature of $\mathrm{N}_{2}$ was correct and that $\mathrm{N}_{2}$ vibrational population is essentially frozen at the facility stagnation condition. Note that in the fitting of the spectra in the non-reacting cases, the wavelength ranges that encompass the hot-bands are omitted from the residual that is minimized by the fitter. This ensures that the fitted (rotational) temperature is unbiased by the assumed vibrational temperature. It is necessary though to have a reasonable estimate of vibrational temperature to fit the composition correctly. The literature indicates that for $\mathrm{N}_{2}$ the vibrational modes of energy typically take roughly three orders of magnitude more collisions to come into equilibrium than the rotational and thermal. ${ }^{19}$ According to Landau-Teller theory ${ }^{19}$ the relaxation time for pure $\mathrm{N}_{2}$ is $\sim 0.28 \mathrm{~ms}$ at the facility stagnation condition and $28 \mathrm{~ms}$ at the nozzle exit condition. Since the nozzle exit velocity is about $1035 \mathrm{~m} / \mathrm{s}$ (i.e., the flow travels the length of the scramjet in roughly $1 \mathrm{~ms}$ ) the observation of vibrationally frozen flow is plausible. (We have neglected the effect of $\mathrm{O}_{2}$ in this calculation.)
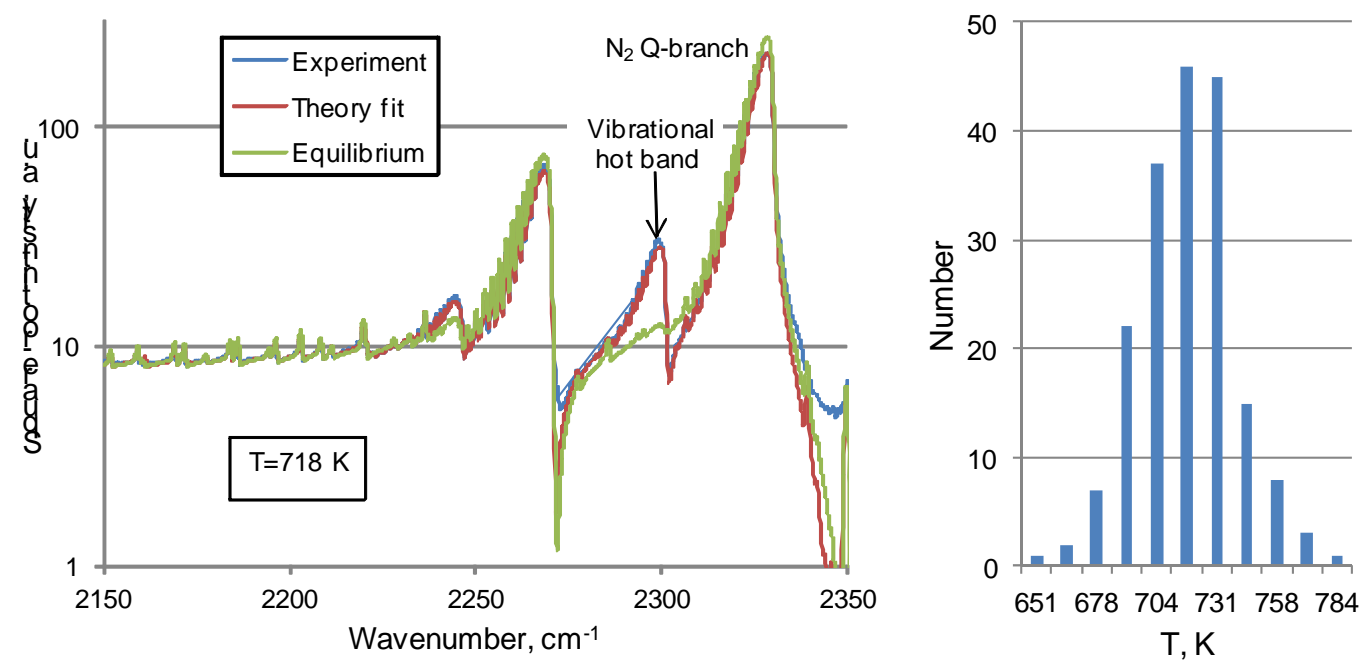

Figure 5. (a) Typical averaged experimental spectrum in the freestream compared to fitted theoretical spectrum assuming non-equilibrium, and to theoretical equilibrium spectrum at the fitted temperature and composition. (b) Histogram of single-shot fitted temperature, at $\mathrm{x} / \mathrm{h}=18, \mathrm{y} / \mathrm{z}=-\mathbf{2 . 0 3}, \mathrm{z} / \mathrm{h}=-\mathbf{0 . 8 9}$ for non-reacting flow $(\varphi=0.12)$.

Figure 6(a) shows similar typical results $\mathrm{x} / \mathrm{h}=12$ for reacting flow $(\varphi=0.17)$, at a location in the plume where $\mathrm{H}_{2}$ and $\mathrm{N}_{2}$ are present, but $\mathrm{O}_{2}$ has been consumed by combustion. In this case the theory assumes vibrational equilibrium and the hot band of $\mathrm{N}_{2}$ is included in the fit. In spectra inside the plume, such as this, where combustion products $\left(\mathrm{H}_{2} \mathrm{O}\right)$ are present, $\mathrm{N}_{2}$ and $\mathrm{O}_{2}$ appear to be in equilibrium. Models in the literature indicate that with only $1 \% \mathrm{H}_{2} \mathrm{O}$ present, at the nozzle exit pressure and temperature, the vibrational relaxation time of $\mathrm{N}_{2}$ is reduced to $5 \mu \mathrm{s}$ (as opposed to many milliseconds), and this time is further reduced by increases in temperature or pressure. ${ }^{20}$ Thus the observation of equilibrium in the combustion products is again plausible.

The histograms of the fitted temperature (parts (b) of the figures) show similar roughly Gaussian distributions of temperature. However, the distribution in Figure 5(b) (which is in the freestream) is relatively narrow, with standard deviation of $22 \mathrm{~K}$, and the distribution in Figure 6(b) (which is in the hotter part of the reacting plume) is broader, with standard deviation $170 \mathrm{~K}$. 


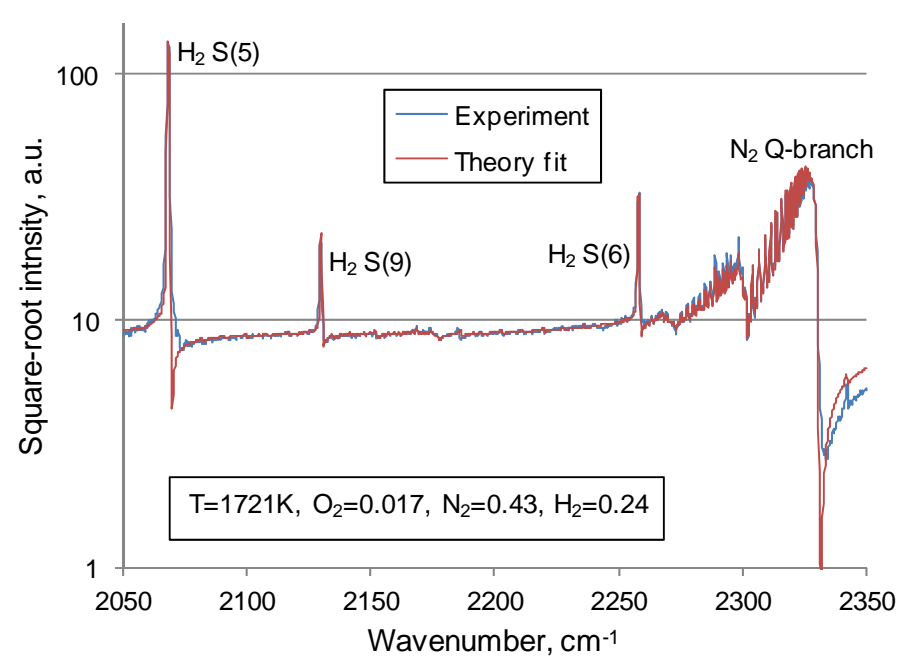

(a)

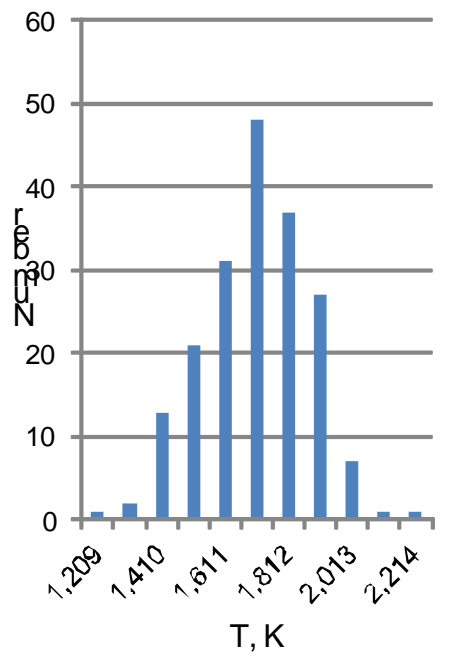

(b)

Figure 6. (a) Typical averaged experimental spectrum compared to fit, and (b) histogram of single-shot fitted temperature, at $\mathrm{x} / \mathrm{h}=12, \mathrm{y} / \mathrm{z}=-\mathbf{1 . 1 0}, \mathrm{z} / \mathrm{h}=\mathbf{2 . 2 5}$ for reacting flow $(\varphi=0.17)$.

The mean and standard deviations of the temperature at the entrance plane (upstream of the fuel injector, at $\mathrm{x} / \mathrm{h}=-$ 10.4) are plotted in Figure 7. These standard deviations include instrument precision error, which adds to the fluctuations of the true temperature in the flow. The limits of the axes are the limits of the flow path $(\mathrm{z} / \mathrm{h}= \pm 3$, $\mathrm{y} / \mathrm{h}= \pm 2$ ). The grid of dots indicates the measurement locations. In these figures, the fuel injection wall is at the top while the CARS beams are horizontal, and the slots in the wall are to the left and right. The data surveys did not extend all the way to the top and bottom walls since the beams are blocked by the walls, nor did it extend into the wall slot on the left; surveys did extend into the slot on the right ( $\mathrm{z} / \mathrm{h}>3$, not shown). The data indicate significant variation of temperature, in particular, a region of low temperature on the top right. Similar results were observed by Stanford using TDLAS (a line of sight absorption technique) ${ }^{21}$ a year previously and with a different scramjet model. In that experiment the facility flow had a few percent steam added to enable the measurement, and thus static temperatures were generally higher, but the trends with the y-direction were the same. Thus we attribute the variations to the facility air heater, rather than to problems with the model or measurement technique. The temperature near the center is around $680 \mathrm{~K}$, in approximate agreement with the static temperature of $667 \mathrm{~K}$, calculated assuming isentropic, vibrationally frozen (i.e., $\gamma=1.4$ ) expansion from the nominal facility total temperature of $1200 \mathrm{~K}$ to Mach 2. (The nominal facility total temperature comes from a thermocouple located at the exit of the heater near the center.) The standard deviations indicate low temperature fluctuations of $20 \mathrm{~K}$ to $30 \mathrm{~K}$ in the bottom left of the flow (which may be largely instrument precision error), while higher fluctuations of about 70 $\mathrm{K}$ are present in the top right. These higher fluctuations may be generated in the heater, but they may also have come about through shear generated turbulence arising from a tendency of the cooler gas in the heater (with lower speed of sound) to accelerate to a lower velocity in the nozzle.

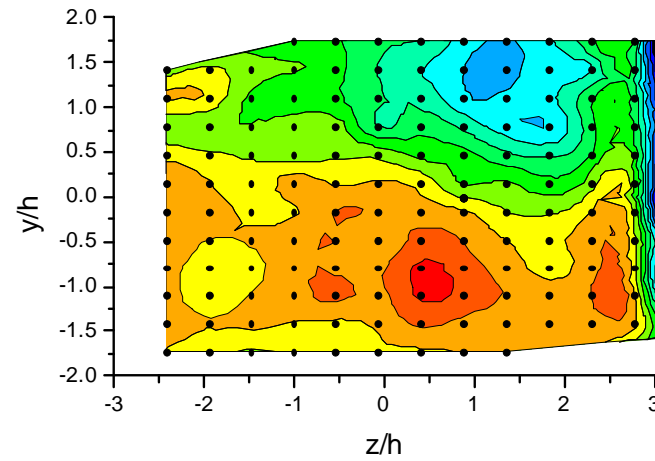

(a)

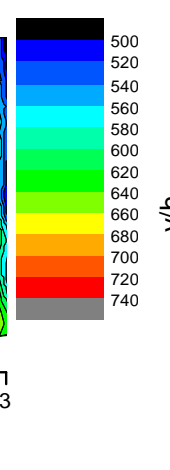

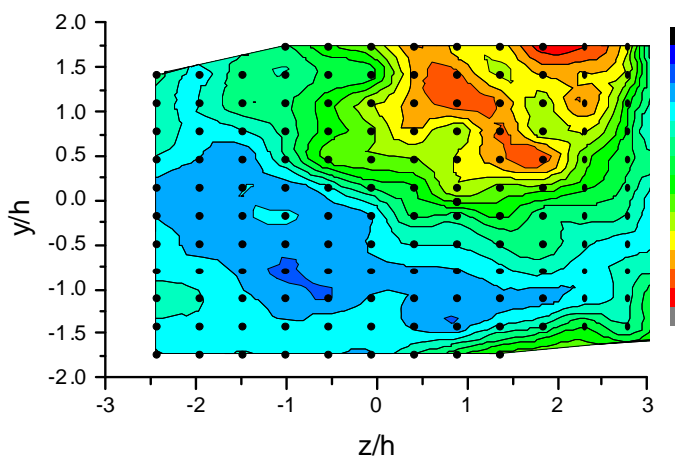

(b)

Figure 7. Contours of (a) mean temperature (K), and (b) standard deviation temperature at the entrance plane $(x / h=-10.4)$. 
Figure 8 shows contours of temperature and mole fractions for the reacting case for $\varphi=0.17$, and $x / h=6,12$, and 18. Unfortunately, due to problems with the translation stage, much of the data for these surveys had to be rejected in postprocessing analysis and the data grids are therefore sparsely populated, particularly at $\mathrm{x} / \mathrm{h}=6$ and 18 ; there is also some uncertainty in position for the remaining data. In (a) at $\mathrm{x} / \mathrm{h}=6$ the temperature is seen to be highest on the injection wall, then at $\mathrm{x} / \mathrm{h}=12$ this hot region has increased in size and temperature and wrapped around the plume, and at $\mathrm{x} / \mathrm{h}=18$ hot products fill the plume. In (b) $\mathrm{H}_{2}$ is seen to occupy the core of the plume while its peak level decreases downstream as it is consumed by reaction. In (c) the level of $\mathrm{N}_{2}$ is seen to increase in the core moving downstream, while in (d) the region where $\mathrm{O}_{2}$ is depleted increases in size between $\mathrm{x} / \mathrm{h}=6$ and 12 .
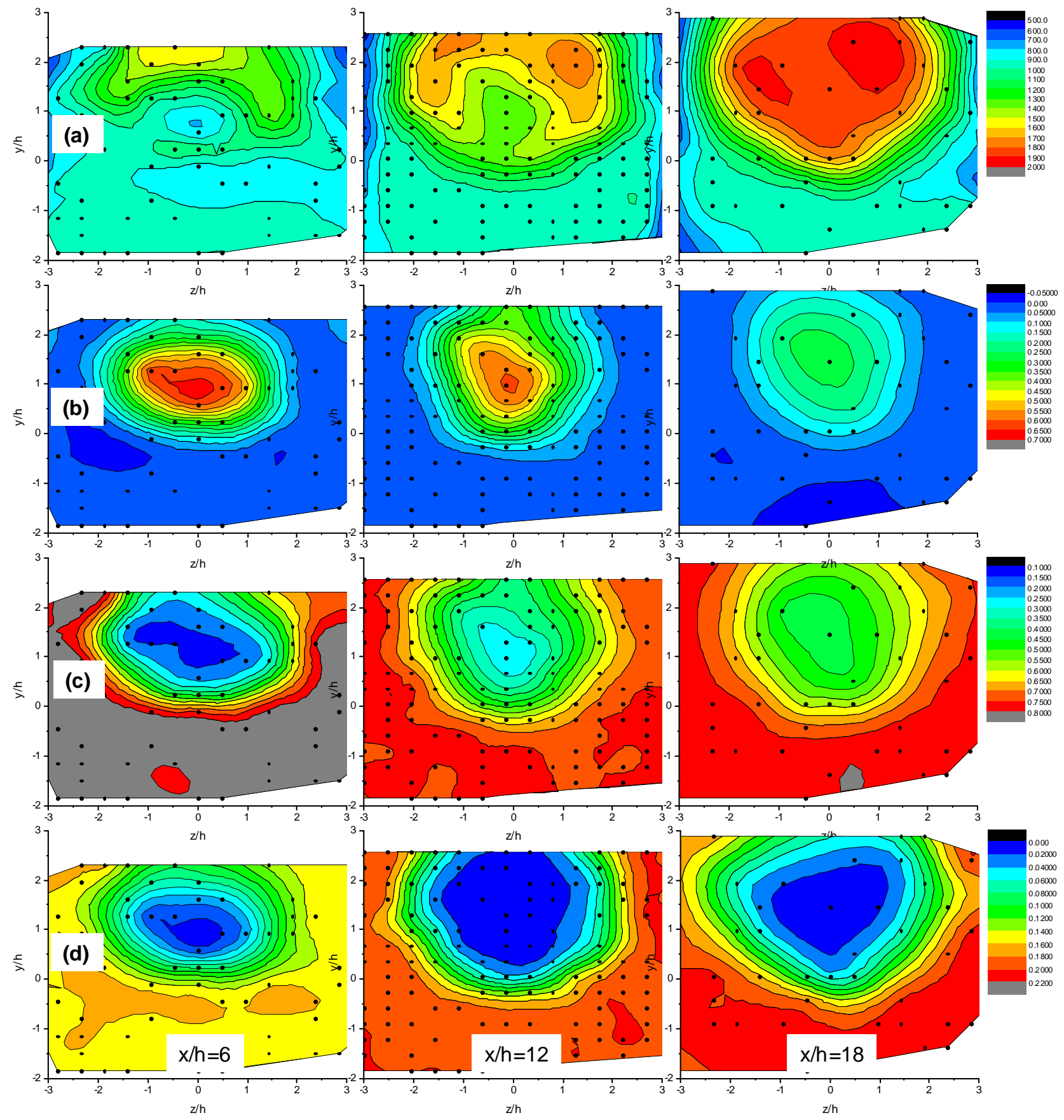

Figure 8. Contours of (a) mean temperature (K), (b) mean mole fraction of $\mathrm{H}_{2}$, (c) $\mathrm{N}_{2}$, and (d) $\mathrm{O}_{2}$ for $\varphi=0.17$ at three planes downstream of fuel injection for the reacting case. 
Figure 9 shows the standard deviation of the fluctuations in temperature and mole fractions for the reacting case for $\varphi=0.17$ at $\mathrm{x} / \mathrm{h}=12$ (the location for which the least data was rejected). Fluctuations are low in the free stream, less than $50 \mathrm{~K}, 0.02,0.04$, and 0.015 in temperature and in the mole fractions of $\mathrm{H}_{2}, \mathrm{~N}_{2}$ and $\mathrm{O}_{2}$ respectively (matching the instrument precision in the case of the mole fractions). The fluctuations are highest at the boundary between the plume and the freestream, towards the outside of this boundary for temperature, $\mathrm{N}_{2}$ and $\mathrm{O}_{2}$, and towards the inside for $\mathrm{H}_{2}$. Fluctuations in the core are less than 0.015 for $\mathrm{O}_{2}$ since little or no $\mathrm{O}_{2}$ remains there. Peak fluctuation levels there are respectively about $300 \mathrm{~K}, 0.2,0.15$, and 0.068 respectively.

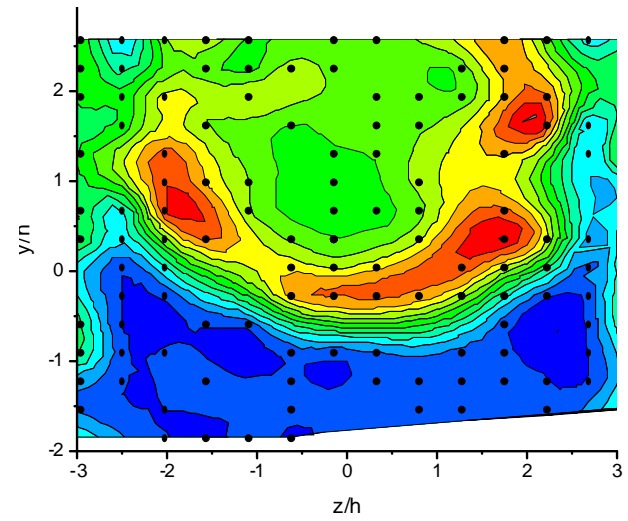

(a)

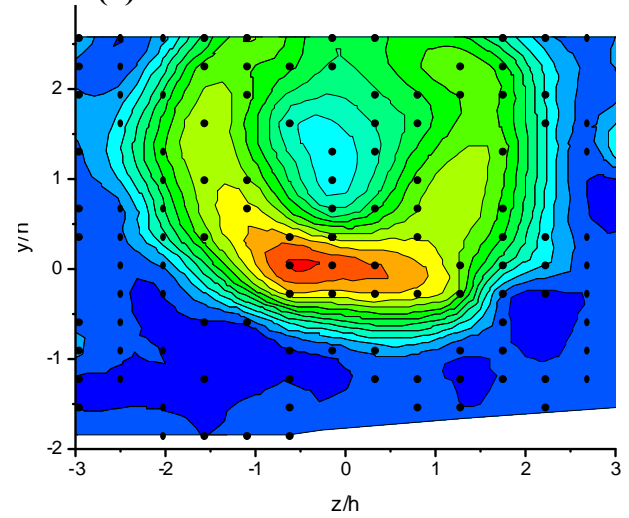

(c)
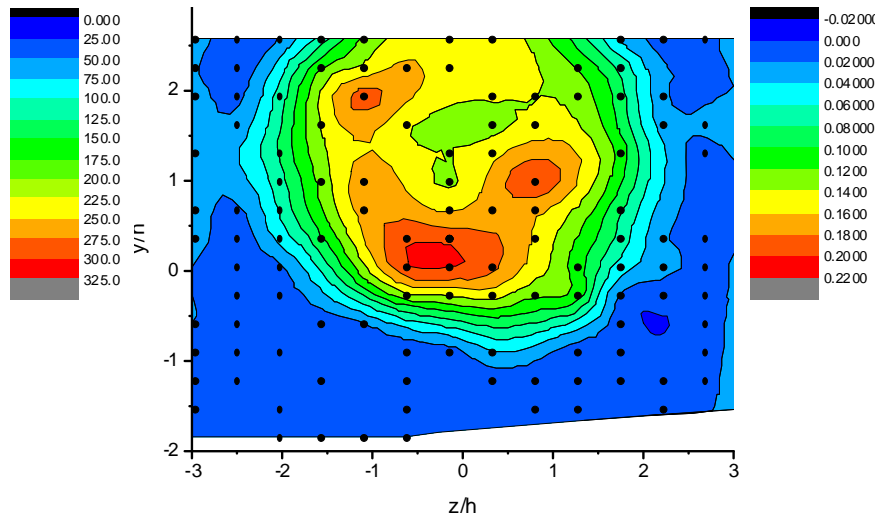

(b)
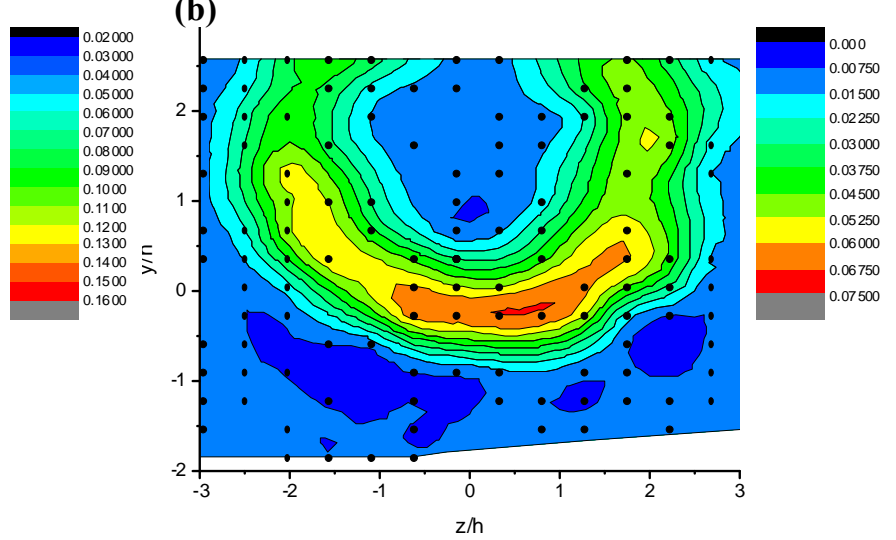

(d)

Figure 9. Contours of the standard deviation of the (a) temperature (K) and of the mole fractions of (b) $\mathrm{H}_{2}$, (c) $\mathrm{N}_{2}$ and (d) $\mathrm{O}_{2}$ for the reacting case for $\varphi=0.17$ at $\mathrm{x} / \mathrm{h}=12$.

Figure 10 shows contours of mean mole fraction of $\mathrm{H}_{2}$, temperature, standard deviation of $\mathrm{H}_{2}$, and standard deviation of temperature for the non-reacting case at $\mathrm{x} / \mathrm{h}=18$. At this plane no problems were encountered with the translation stage and the grid is complete. However, due to a problem with the fuel system when this data was acquired, the target equivalence ratio of 0.17 was not accomplished and instead was $\varphi=0.12$. Non-reacting data were also acquired at $\mathrm{x} / \mathrm{h}=6$ and 12 (for $\varphi=0.17$ ), but due to a combination of the rejection of a large number of points and the smaller size of the plume, the number of points within the plume was so few as to make the data less useful. This figure shows the plume of $\mathrm{H}_{2}$ (a) to be much smaller than the plume of $\mathrm{H}_{2}$ and hot products when reacting, which cannot simply be attributed to the lower $\varphi$. Temperatures in the plume (b) are significantly lower than in the reacting case since the $\mathrm{H}_{2}$ is unheated prior to injection and there is no reaction. Notice the lower temperature to the right of the plume as compared to the left: this is attributed to the non-uniformity of the temperature in the heater, as discussed in relation to the entrance plane temperature measurements (Figure 7). Mole fraction $\mathrm{H}_{2}$ fluctuations (c) peak at the outer edge of the plume, as do the temperature fluctuations (d). 


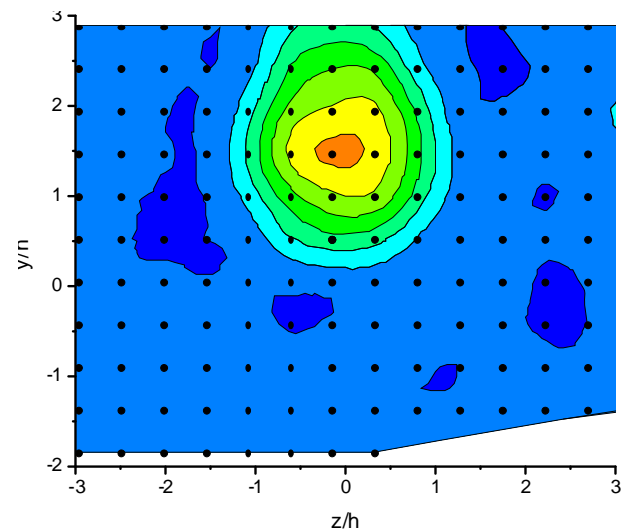

(a)

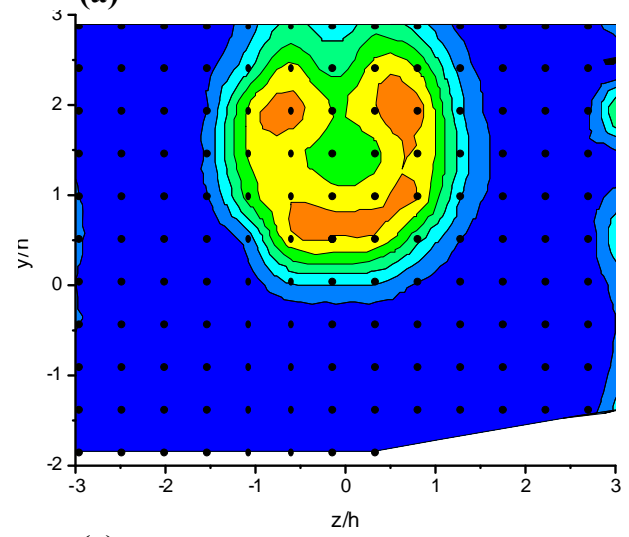

(c)
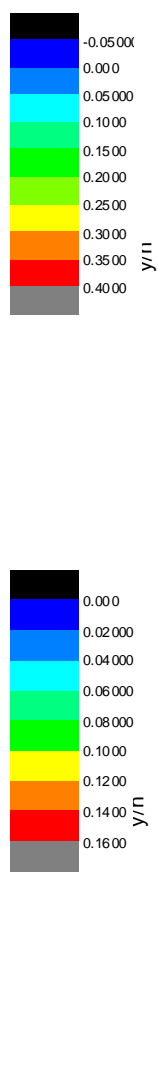

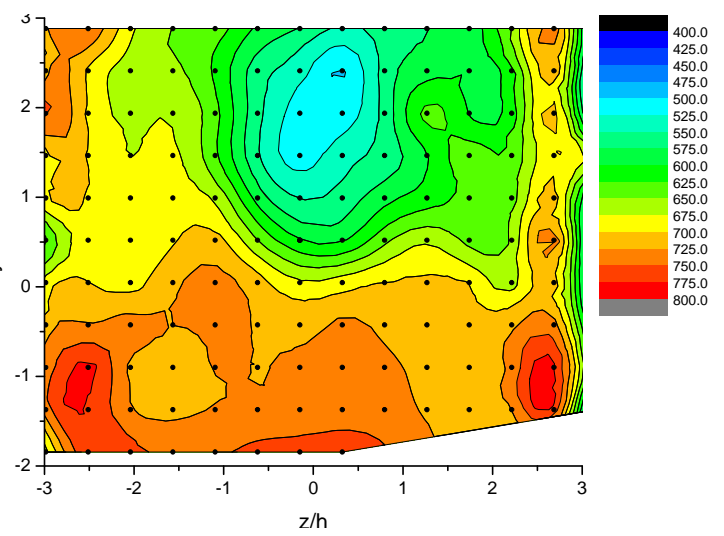

(b)

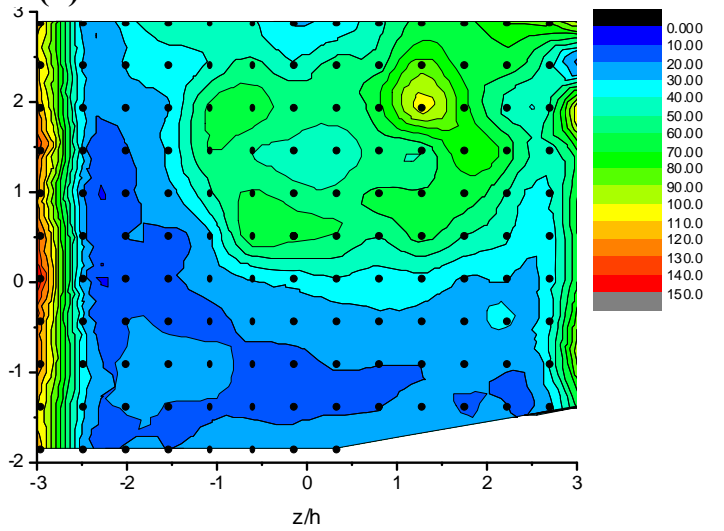

(d)

Figure 10. Contours of (a) mean mole fraction of $\mathrm{H}_{2}$, (b) temperature (K), (c) standard deviation of $\mathrm{H}_{2}$, and (e) standard deviation of temperature for the non-reacting case at $\varphi=0.12, x / h=18$.

Uncertainties in our measurement techniques have been discussed in detail by Magnotti. ${ }^{12}$ The instrument precision stated therein (defined as \pm one standard deviation) is $<3.3 \%$ in temperature, $<1.8 \%$ in $\mathrm{O}_{2}$ and $<3.4 \%$ in $\mathrm{N}_{2}$, both as a percentage of the total composition, and $<10 \%$ in $\mathrm{H}_{2}$ mole fractions, as a percent of the measured value. Mole fraction bias uncertainty for temperatures above $600 \mathrm{~K}$ is $0.5 \%, 1.5 \%$ and $1 \%$ of the total composition for $\mathrm{O}_{2}, \mathrm{~N}_{2}$ and $\mathrm{H}_{2}$, respectively. One major source of uncertainty is in the reference spectrum, and the mole fraction is particularly susceptible to errors in this spectrum. Magnotti described how the center of this spectrum steadily shifts in wavelength during the experiment. When the reference spectrum is correct then the normalized spectra have constant intensity at wavelengths away from molecular resonances, whereas if it is incorrect there are variations of these non-resonant portions of the spectra. It is therefore possible to assess the correctness of the reference spectra (and institute corrections if need be) by inspection of spectra measured in the center of the fuel plume, where $\mathrm{N}_{2}$ and $\mathrm{O}_{2}$ compositions are low (and $\mathrm{H}_{2}$ resonances are limited to a few discrete lines). In the present work we found in some instances that problems could not be simply corrected by a change in center wavelength. We speculate that this may be because our reference spectra were obtained in an argon jet outside the scramjet model, in the absence of the model windows (or compensating optics). The absence of the windows changes the collimation and path of the signal beam to the spectrometer. In the future, we will investigate this source of error and institute changes to our methods.

In a concurrent paper, comparisons with computational predictions of the flow employing the Reynoldsaveraged Navier-Stokes and large-eddy simulation techniques are presented. ${ }^{22}$ The data are proving useful in the assessment of the computational results.

\section{Conclusions and Future Work}

In this paper we have described an application of our dual-pump CARS system to the University of Virginia's dual-mode scramjet facility, and shown the results of our first CARS measurement campaign. These measurements have successfully resulted in a better understanding of the facility operation and the mixing and combustion processes in the scramjet combustor. We have documented non-uniformities in temperature of the flow exiting the 
heater of the facility, and have demonstrated that the vibrational energy mode of the airstream in the combustor is frozen at close to the facility heater temperature. We have developed a data base that is already being used by the computational modelers and has also enabled validation of initial numerical models. A number of experimental difficulties we encountered along with experimental uncertainties are described. Importantly, the lessons learned in this first measurement campaign will lead to improved techniques in future experiments.

In the near future, similar measurements at multiple equivalence ratios are planned in this facility after the scramjet model is modified by the addition of an inlet isolator (more typical of a scramjet in the ram-scram transition regime). Subsequently, our techniques will be adapted for use in gaseous ethylene flames while the UVa scramjet will be modified for ethylene combustion, and then further CARS data sets acquired.

\section{Acknowledgments}

The authors would like to thank Roger Reynolds (University of Virginia) for his support and operation of the wind tunnel and Simone Eichmann (University of Erlangen) for her optical expertise and contributions in the laboratory. This research was sponsored by the National Center for Hypersonic Combined Cycle Propulsion grant FA 9550-09-1-0611. The technical monitors on the grant are Chiping Li (AFOSR), and Aaron Auslender and Rick Gaffney (NASA). Support for Paul Danehy was provided by NASA's Fundamental Aeronautics Program, Hypersonics Project, Propulsion Discipline.

\section{References}

${ }^{1}$ McDaniel, J.C., Chelliah, H., Goyne, C.P., Edwards, J.R., Givi, P., Cutler, A.D., "US National Center for Hypersonic Combined Cycle Propulsion: An Overview," AIAA-2009-7280, 16th AIAA/DLR/DGLR International Space Planes and Hypersonic Systems and Technologies Conference, Bremen, Germany, Oct 2009.

${ }^{2}$ O'Byrne, S., Danehy, P.M., Tedder, S.A., Cutler, A.D., "Dual-Pump Coherent Anti-Stokes Raman Scattering Measurements in a Supersonic Combustor," AIAA Journal, Vol. 45, No. 4, p. 922-933, April 2007.

${ }^{3}$ Tedder, S.A., Danehy, P.M., Magnotti, G., Cutler, A.D., "CARS Temperature Measurements in a CombustionHeated Mach 1.6 Jet", AIAA-2009-0524, $47^{\text {th }}$ AIAA Aerospace Sciences Meeting, Orlando, FL, January, 2009.

${ }^{4}$ Bivolaru, D., Cutler, A.D., Danehy, P.M., Gaffney, R.L., Jr, Baurle, R.A., "Spatially and Temporally Resolved Measurements of Velocity in a H2-air Combustion-heated Supersonic jet," AIAA-2009-0027, $47^{\text {th }}$ AIAA Aerospace Sciences Meeting, Orlando, FL, January, 2009.

${ }^{5}$ Rockwell, RD, Goyne, CP, Rice, BE, Tatman, BJ, McDaniel, JV, and Edwards, JR, "Close-collaborative Experimental and Computational Study of a Dual-mode Scramjet Combustor," 50 ${ }^{\text {th }}$ AIAA Aerospace Sciences Meeting and Exhibit, Nashville, TN, 2012 (submitted for publication).

${ }^{6}$ Lucht, R.P., "Three-laser coherent anti-Stokes Raman scattering measurements of two species," Optics Letters, Vol. 12, No. 2, February 1987, pp. 78-80.

${ }^{7}$ Hancock, R.D., Schauer, F.R., Lucht, R.P. and Farrow, R.L., "Dual-pump coherent anti-Stokes Raman scattering measurements of nitrogen and oxygen in a laminar jet diffusion flame," Applied Optics, Vol. 36, No. 15, 1997.

${ }^{8}$ Cutler, A.D., Danehy, P.M., Springer, R.R., O’Byrne, S., Capriotti, D.P., DeLoach, R., "Coherent Anti-Stokes Raman Spectroscopic Thermometry in a Supersonic Combustor," AIAA J., Vol. 41, No. 12, Dec. 2003.

${ }_{9}^{9}$ O’Byrne, S., Danehy, P.M., Tedder, S.A., Cutler, A.D., "Dual-Pump Coherent Anti-Stokes Raman Scattering Measurements in a Supersonic Combustor," AIAA Journal, Vol. 45, No. 4, p. 922-933, April 2007

${ }^{10}$ Cutler, A.D., Magnotti, G., "CARS Spectral Fitting with Multiple Resonant Species Using Sparse Libraries," in press, J. Raman Spectroscopy, 2011.

${ }^{11}$ Magnotti, G., Cutler, A.D., Herring, G.C., Tedder, S.A., Danehy, P.M., "Saturation and Stark Broadening Effects in Dual-Pump CARS of $\mathrm{N}_{2}, \mathrm{O}_{2}$ and $\mathrm{H}_{2}$," accepted for publication, J. Raman Spectroscopy, 2011

${ }^{12}$ Magnotti, G., Cutler, A.D., Danehy, P.M., "Dual-Pump CARS Measurements in a Supersonic Combusting Free Jet," $50^{\text {th }}$ AIAA Aerospace Sciences Meeting, Nashville, TN, January, 2012 (submitted for publication).

${ }^{13}$ Krauss, R.H., McDaniel, J.C., Scott J.E., Whitehurst, R.B., Segal, C., Mahoney, G.T., and Childers, J.M., "Unique, clean-air, continuous-flow, high-stagnation-temperature facility for supersonic combustion research," AIAA Paper 88-3059, July, 1988.

${ }^{14}$ Krauss, R.H., and McDaniel, J.C., “A Clean Air Continuous Flow Propulsion Facility,” AIAA Paper 92-3912, July, 1992.

${ }^{15}$ Magnotti, G., Cutler, A. D., and Danehy, P. M. "Beam Shaping for CARS Measurements in Turbulent Environments," AIAA-2010-1400 48th AIAA Aerospace Sciences Meeting, Orlando, FL, 2010 
${ }^{16}$ Bivolaru, D., and Herring, G. C., "Focal Plane Imaging of Crossed Beams in Non-linearOptics Experiments," Review of Scientific Instruments Vol. 78, No. 5, 2007.

${ }^{17}$ Palmer, R.E, The CARSFT Computer Code for Calculating Coherent Anti-Stokes Raman Spectra: User and Programmer Information, Sandia report SAND89-8206, Feb 1989.

${ }^{18}$ Kojima J., Nguyen Q., "Quantitative analysis of spectral interference of spontaneous Raman scattering in highpressure fuel rich $\mathrm{H}_{2}$-air combustion," Journal of Quantitative Spectroscopy \& Radiative Heat Transfer, Vol. 94, 2005, pp 439-466, 2005.

${ }^{19}$ Vincenti, W.G., Kruger, C.H., Introduction to Gas Dynamics, Robert Krieger Pub. Co., New York, 1977.

${ }^{20}$ Center, R.E., Newton, J.F., "Vibrational Relaxation of $\mathrm{N}_{2}$ by $\mathrm{H}_{2} \mathrm{O}$," J. Chem Phys., Vol. 68, No. 8, April 1978.

${ }^{21}$ Goldenstein, C., Schultz, I., Jeffries, J., Hanson, R., "Tunable Diode Laser Absorption Sensor for Measurements of Temperature and Water Concentration in Supersonic Flows," AIAA-2011-1094, 49 ${ }^{\text {th }}$ AIAA Aerospace Sciences Meeting, Orlando, FL, Jan. 4-7, 2011.

${ }^{22}$ Fulton, J.A., Edwards, J.R., and Hassan, H.A. "Large-eddy / Reynolds-averaged Navier-Stokes Simulation of a Dual-Mode Scramjet Combustor,” 50 $0^{\text {th }}$ AIAA Aerospace Sciences Meeting, Nashville, TN, January, 2012 (submitted for publication). 